\title{
Revista
}

Contemporânea de

\section{Normas gerais}

1.1 - A Revista Contemporânea de Contabilidade (ISSN 1807-1821), do Curso de Ciências Contábeis e do Programa de Pós-Graduação em Contabilidade da UFSC, destina-se à publicação de textos inéditos nas modalidades de artigo, resenha, opinião, entrevista, pesquisa científica e demais trabalhos acadêmicos.

1.2 - A Revista Contemporânea de Contabilidade reserva-se o direito de submeter todos os originais à apreciação do Editor, Comitê de Política Editorial e Conselho Editorial Científico, que dispõem de plena autoridade para decidir sobre a conveniência ou não da publicação podendo, inclusive, reapresentá-los aos autores, com sugestões para que sejam feitas alterações necessárias no texto e/ou para que os adaptem às normas editoriais da Revista. Neste caso, os referidos trabalhos serão reavaliados pelos avaliadores.

1.3 - Os trabalhos enviados para publicação devem ser inéditos, não sendo permitida a sua apresentação simultânea em outro periódico. A Revista Contemporânea de Contabilidade se reserva todos os direitos autorais do trabalho publicado, inclusive de tradução, permitindo, entretanto, a sua posterior reprodução com a devida citação de fonte.

1.4 - A Revista Contemporânea de Contabilidade está aberta a colaborações do Brasil e do exterior, tanto do campo de Contabilidade como de áreas afins e suas relações interdisciplinares.A pluralidade de abordagens e perspectivas é incentivada.

1.5 - Caberá a cada autor de artigo publicado pela Revista dois exemplares do número em questão como única indenização por direitos autorais.

1.6 - Não serão publicadas fotos coloridas, a não ser em casos de absoluta necessidade e a critério da comissão editorial, com custos para os autores. 


\section{Da apresentação original}

Os originais destinados à Revista Contemporânea de Contabilidade deverão ser redigidos de acordo com o seguinte formato:

2.1- Redação na ortografia oficial e digitação em folhas de papel tamanho A4 (210 mm x $297 \mathrm{~mm}$ ) no editor de texto Word for Windows 6.0 ou posterior, com espaço duplo; e margens (superior e esquerda de $3 \mathrm{~cm}$ e inferior e direita de 2 cm). O artigo não deverá exceder 20 laudas, inlcuindo quadro, tabelas, gráficos, ilustrações, notas e referências bibliográficas; fonte Times New Roman, tamanho 12, exceto para o título.

\section{2 - Ilustrações:}

- devem ser de boa qualidade;

- gráficos devem ser apresentados no programa Excel, Word ou Power Point.

\section{3 - Tabelas e quadros:}

- legendas serão colocadas na parte superior, observando as normas da ABNT atualizada.

2.4 - As notas de rodapé devem ser evitadas. Caso sejam imprescindíveis, as mesmas devem ser apresentadas após a conclusão do artigo.

2.5 - No preparo do original, deverá ser observada a seguinte estrutura:

a) Cabeçalho:

- Título do artigo (em português e inglês);

- Nome completo(s) do(s) autor(es), com titulação, instituição de origem, endereço, e-mail e telefone, conforme modelo abaixo:

Sandra Rolim Ensslin

Dra. em Engenharia de Produção na Universidade Federal de Santa Catarina Professora do Mestrado em Contabilidade da Universidade Federal de Santa Catarina

Endereço: Rua Itararé, $n^{\circ}$ 6627, Bairro Itacorubi

CEP: 88000-000 - Florianópolis/SC - Brasil

E-mail: sensslin@gmail.com

Telefone: (48) 3721-6662

b) Resumo:

- Resumo em português, com até 100 palavras, alinhamento justificado.

c) Palavras-chave:

- Até 5 palavras ou expressões, alinhadas à esquerda, que identifiquem o 
conteúdo do artigo.

d) Abstract:

- Consiste na apresentação concisa em inglês do resumo.

e) Key words:

- Correspondem às palavras ou expressões em inglês que identifiquem o conteúdo do artigo.

f) Texto:

- Introdução, material e método, resultados, discussão, conclusões.

g) Referências bibliográficas:

- Ordenadas alfabeticamente pelo sobrenome do autor, conforme normas da ABNT.

h) Endereço dos autores:

- Deverão constar, no final dos trabalhos, endereço completo, telefone, fax e e-mail de pelo menos um dos autores.

2.6 - O número de autores deve ser no máximo de 5 (cinco) integrantes.

\section{3 - Forma de envio}

Os artigos deverão ser submetidos via plataforma em http://www.periodicos.ufsc. br/index.php/contabilidade/about/submissions\#onlineSubmissions. No caso é necessário preencher o cadastro - http://www.periodicos.ufsc.br/index.php/contabilidade/user/register - preencher o formulário para se cadastrar no sistema. Em seguida utilize o link Autor e inicie o processo de submissão do artigo. São cinco passos, lembre de salvar no final de cada etapa: 1. Início 2. Inclusão de Metadados 3. Transferência do Manuscrito 4. Transferência de Documentos Suplementares 5. Confirmação. Lembre de retirar o(s) nome(s) da autoria do arquivo.

Em casos excepcionais poderá ser enviado pelo correio eletrônico em "attach" para o e-mail: rcc@mbox1.ufsc.br, constando, no assunto, a seguinte informação: artigo para a Revista Contemporânea de Contabilidade.

\section{4 - Processo de avaliação}

O objetivo do processo de avaliação é ajudar nossos colaboradores a melhorar seus trabalhos, fornecendo avaliações construtivistas, preparadas por especialistas experientes.

Os originais de artigos e resenhas submetidos à RCC são encaminhados para a apreciação de, pelo menos dois, pareceristas integrantes do Conselho Editorial 
Científico ou consultores "ad hoc". Neste processo, os originais são lidos inicialmente pelo Editor que, se considerar estarem de acordo com a linha editorial geral, os encaminhará para os pareceristas.

Todos os trabalhos são avaliados com base nos critérios previamente estabelecidos pelo Comitê de Política Editorial, utilizando-se de um instrumento elaborado para esta finalidade, conforme apresentado a seguir:

\section{AVALIAÇZ̃ O DE ARTIGO}

\begin{tabular}{|l|l|}
\hline Nome d Avaliador: & Dota-prazo: \\
\hline & \\
\hline Tixulo do Artiga: & \\
\hline
\end{tabular}

\section{1 - GRI TÉRI OS DE A'VALIAGä́}

\begin{tabular}{|c|c|}
\hline 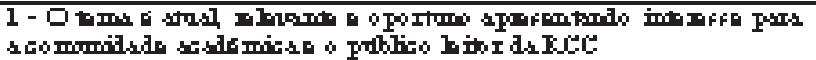 & \\
\hline 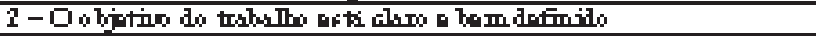 & \\
\hline 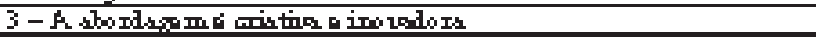 & \\
\hline 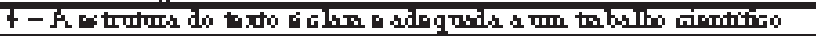 & \\
\hline 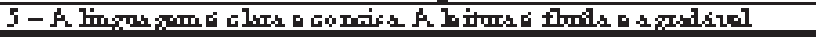 & \\
\hline 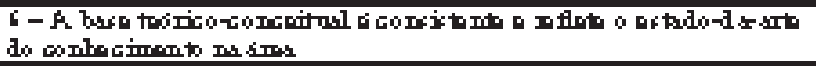 & \\
\hline 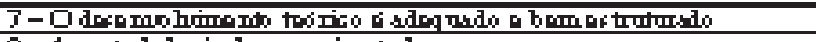 & \\
\hline 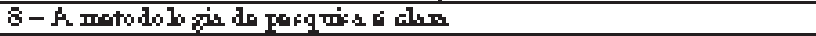 & \\
\hline 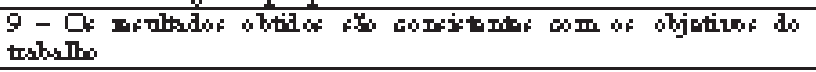 & \\
\hline 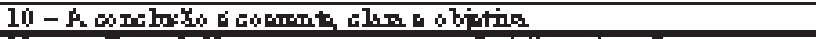 & \\
\hline 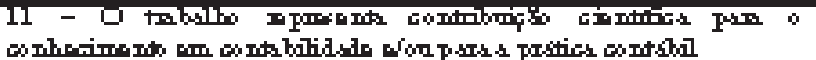 & \\
\hline
\end{tabular}

\section{2 - PONTOS FORTES E FRACOS}

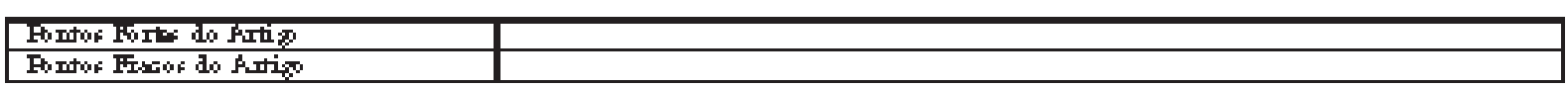

\section{3 - SUGESTÖES}

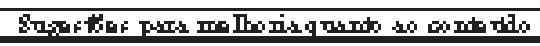

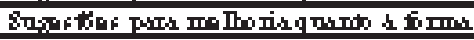

\section{4 - COMENTÁRIOS ADIGIONAIS}

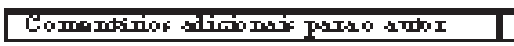

\section{5 - RECO MENAGGÃO FNAL}

O tmbal ho dow ser aprovado mra putli mgāose m restriçōs

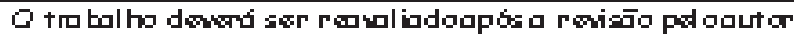

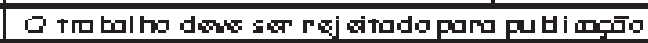


A seguir, o trabalho é enviado aos autores para que procedam às modificações necessárias, quando solicitadas.

Após a aprovação o artigo é encaminhado para Revisão Gramatical e de Normalização

Quando houver a necessidade de alterações referentes apenas a aspectos gramaticais, ortográficos e de ordem normativa, com vistas a manter a homogeneidade da publicação, a revisora de redação se dá o direito de fazer as modificações necessárias, respeitando o estilo do autor. Nos demais casos, o autor reformulará o texto conforme o que for solicitado pela Comissão.

Os artigos e demais trabalhos publicados na Revista Contemporânea de Contabilidade, passam a ser propriedade da revista. Uma nova publicação do mesmo texto, de iniciativa de seu autor ou de terceiros, fica sujeita à expressa menção da precedência de sua publicação neste periódico, citando-se a edição e data dessa publicação.

A Revista Contemporânea de Contabilidade não se responsabiliza ou endossa as opiniões emitidas pelos autores dos textos nela publicados, salientando que as opiniões são de sua exclusiva responsabilidade.

abalho é enviado aos autores para que procedam às modificações necessárias, quando solicitadas.

Após a aprovação o artigo é encaminhado para Revisão Gramatical e de Normalização

Quando houver a necessidade de alterações referentes apenas a aspectos gramaticais, ortográficos e de ordem normativa, com vistas a manter a homogeneidade da publicação, a revisora de redação se dá o direito de fazer as modificações necessárias, respeitando o estilo do autor. Nos demais casos, o autor reformulará o texto conforme o que for solicitado pela Comissão.

Os artigos e demais trabalhos publicados na Revista Contemporânea de Contabilidade, passam a ser propriedade da revista. Uma nova publicação do mesmo texto, de iniciativa de seu autor ou de terceiros, fica sujeita à expressa menção da precedência de sua publicação neste periódico, citando-se a edição e data dessa publicação.

A Revista Contemporânea de Contabilidade não se responsabiliza ou endossa as 
opiniões emitidas pelos autores dos textos nela publicados, salientando que as opiniões são de sua exclusiva responsabilidade. 